\title{
A Theoretical Framework for Examining IT Governance in Living Laboratory Ecosystems
}

\author{
Trevor Clohessy, Lorraine Morgan, and Thomas Acton \\ Business Information Systems, Whitaker Institute, \\ National University of Ireland Galway, Ireland \& Lero - \\ The Irish Software Engineering Research Centre, Ireland \\ \{t.clohessy2, 1.morgan, thomas.acton\} @nuigalway.ie
}

\begin{abstract}
In recent years Living Labs, which embody an open innovation milieu, have gained currency as representing a salient catalyst for Smart City research and development. However, the current body of Living Lab research, in conjunction with the fragmented isolated nature of existing Living Labs dispersed across the European Union (EU), indicate that a lack of common standardised IT governance procedures are currently being operationalised. While cross border pan European Living Lab initiatives are emerging to rectify this issue, further research is warranted to better understand the role of IT governance in Living Labs and identify how varying IT governance mechanisms impact the effectiveness of open innovation processes. Thus, this paper begins a theory building process for examining IT governance in living labs. The paper concludes by presenting a conceptual framework for future testing.
\end{abstract}

Keywords: Smart City, Living Laboratory, Open Innovation, IT Governance.

\section{Introduction}

A "smart city", also known in the guises of intelligent city, information city, digital city, e-city and virtual city, has been identified as being an exemplary example of a response to address the current and future complex challenges of increasing resource efficiency, reducing emissions, sustainable health care services for ageing populations, empowering youth and integrating minorities [1, 2]. Kanter and Litow [3] profess their vision for future smart cities in which world leaders combine technological capabilities and social innovation to enable the development of a smarter, sentient even, world comprising smarter communities that sustain the eudaemonia of all citizens. Cities however "can only be smart if there are intelligence functions that are able to integrate and synthesise data to some purpose, ways of improving the efficiency, equity, sustainability and quality of life in cities"[4]. Batty, et al. [4] propose a typology which delineates the typical functions inherent in a smart city comprising smart economy (competitiveness), smart people (social and human capital), smart governance (participation), smart mobility (transport and information, communication and technology), smart environment (natural resources) and smart living (quality of life). 
The requirement for participatory government, a concept which refers to the empowerment of cities citizens, a form of "democratic innovation", first popularised by Von Hippel [5], denotes the increasing ability of enterprises and consumers, utilising software products and services, to innovate for themselves. Nam and Pardo [6] affirm that "as urban planning is based on governance with multiple stakeholders is pivotal to smart growth, smart city initiatives necessitate governance for their success". The use of emerging nascent IT computing can enable the "development of smart governance infrastructures which provide transparency of public efforts, promotes cultural flourishing and can increase accountability [7].

The concept of a Living Laboratory (Living Lab) has emerged as an exemplar of an integrated open innovation user-driven ecosystem approach in the advancement of smart city research, enabling the foundation for the establishment of large, open and federated experimental facilities, which are required prior to the deployment and operationalisation of real-life smart urban infrastructure and services [1, 8, 9]. Living Labs require new forms of IT governance which reflect the characteristics of emerging IT solutions and open source ecosystems that "favour wide knowledge sharing and communication, networking and partnering" [10]. Currently, there is a paucity of research that examines governance mechanisms in living labs and their impact on open innovation effectiveness. Thus, we respond to this research gap by theorising the role of IT governance in Living Lab ecosystems.

The remainder of the paper is structured as follows. The next section builds the theoretical background for our analysis. The subsequent section delineates the resulting theoretical model of relationships and constructs underlying this study. The final section presents concluding remarks.

\section{Theoretical Background}

\subsection{The Open Innovation Process}

It has been argued that organisations that actively engage in an open innovation process may be rewarded with valuable strategic innovations [11]. Chesbrough [12] opines that the design and subsequent management of end user open innovation driven communities will play a pivotal role in the future of open innovation. An organisation's capability to mould strategic innovations is enabled by utilising technology created by others, or by allowing others to use their technology [13]. Thus, open innovation may be defined as a process of "systematically relying on a firm's dynamic capabilities of internally and externally carrying out the major technology management tasks, i.e., technology acquisition and technology exploitation, along the innovation process" [14]. According to van de Vrande et al., [15] as open innovation is a consequence of managerial practices that encompass integrative innovation management activities such as business strategy, collaborative agreements and innovation partners, further research is required into the open innovation domain with regard to external technology acquisition and cooperation amongst stakeholders. Feller et al., [44] argue that "dramatic reductions in innovation cycles and increasing globalisation will continue to force organisations to explore more avenues for leveraging external entities to enhance their ability to innovate." To that end, we explore the concept of a Living Lab as an avenue for leveraging open innovation capabilities. 


\subsection{The Living Lab Approach}

A Living Laboratory is defined as "a user-centred open innovation ecosystem integrating concurrent research and innovation processes" [16] within public-private-civic partnerships where IT "innovations are created and validated in collaborative multicontextual empirical real-world environments"[10]. It is this multi-contextual dimension which bestows the Living Lab concept a distinct advantage over traditional user-centric methodologies [17]. The European Network of Living Labs (ENoLL) is the international federation of benchmarked Living Labs in Europe and worldwide and currently provisions strategic guidance to over 300 Living Labs. Living Labs, which embody open business models of collaboration, represent a fundamental methodology for the manner in which open innovation user-driven ecosystems should be organised [1].

The Living Lab concept is similar in its approach to other open methodologies such as open innovation [18], communities of creation [19], democratic user - driven innovation [5], crowdsourcing [20] and also contains characteristics inherent in user centric approaches such as participatory design and socio-technical design [21]. In recent years, Living Labs have "proved to be an effective means to close the gap between innovative research and development $(R \& D)$ in the smart city arena and market take-up, and make the innovation process more effective" [9]. They facilitate the engagement of users to tackle specific salient $R \& D$ issues which are relevant to the development of smart cities such as multi-stakeholder participation, organisational processes and structures, behavioral change and innovation, IT governance, business modelling change and impact assessment and cultural specificities [9].

\section{Building the Theoretical Framework}

In order to address our research questions, we engage in a process of theory building as proposed by Dubin [22], Whetten [23] and Reynolds [24] whereby we analyse the extant research and delineate constructs and relationships between them in the form of theoretical propositions.

\subsection{Delineating IT Governance}

According to Brown and Grant [25] the concept of IT governance has its origins as early as the 1960s where researchers attempted to address a number of fundamental concepts which directly mirror modern day definitions of IT governance. Weill [26] proclaim that "effective IT governance encourages and leverages the ingenuity of all enterprise personnel in using IT, while ensuring compliance with the enterprise's overall vision and principle...good IT governance can achieve a management paradox: simultaneously empowering and controlling". Additionally, effective IT governance has been identified as being a critical issue for preventing financial, operational and strategic impairment [27]. However, IT governance has been described as being a “ephemeral and 'messy' phenomenon, emerging in ever-new forms with increasing complexity" [28]. This author utilises an ancient Indian fable, 'the blind men and the elephant', to highlight how the complexity of IT governance systems in conjunction with the blinkered focused strategic objectives of principal stakeholders can impede 
effective governance of IT. It is now widely recognised that "getting IT right" does not stem merely from the technology, but stems principally from effective (distributed) IT governance [28]. According to De Haes and Van Grembergen [29] three levels of IT governance exist: strategic level (board of directors), management level (executive management) and operational level (IT and business management). The authors argue that whilst some IT governance practices can be applied solely on one specific level, other practices can be applied at multiple levels. In terms of concreting an IT governance definition, sufficient consensus has not been reached, mainly due to the divergence in IT governance research over the last decade on an accepted definition [30]. However, for the purpose of the study, we have selected a definition which appropriately embodies the concept of a Living Lab, an ecosystem which encapsulates a multitude of stakeholders whose decisions on strategic IT are articulated, where IT governance is defined as "the distribution of IT decision-making rights and responsibilities among stakeholders...the procedures and mechanisms for making and monitoring strategic decisions regarding IT" [28].

\subsection{Living Lab IT Governance}

According to Ballon, et al. [9] existing European based Living Lab initiatives are largely isolated and fragmented, mainly as a consequence of the operationalisation of varying IT governance processes within Living Lab environments which is compounded by language and regional barriers. These deficiencies are culminating in the failure of Living Labs, not only to effectively promote and share innovation across European public sectors, but also failing to address the ramifications that these siloed IT governance procedures may have on the effectiveness of open innovation processes and on the development of future smart city IT governance policies. Peterson [28] argues that "emerging paradigms for IT governance, are based on collaboration, not control, where the need for distinct competencies is recognized, developed, and shared adaptively across functional, organizational, cultural and geographic boundaries". The emergence of open, pan European platform initiatives such as the European Platform for Intelligent Cities (EPIC) are paving the way for smarter cities to exchange practical reference models that may be operationalized in real life contexts. Nonetheless, further research is warranted to identify how suitable IT governance mechanisms facilitate effective open innovation activities in Living Lab ecosystems. It is envisaged that Living Lab ecosystems with successful governance will have proactively designed a cogent combination of governance mechanisms (e.g., IT organisational structures, committees, monitoring procedures, active stakeholder relationship management, aligned incentives and so on) that stimulate behaviours, which are in keeping with the ecosystem's mission, strategy, culture, norms and values [26]. The process of determining the correct IT governance architecture is a "complex endeavour and it should be recognised that what strategically works for one organisation does not necessarily work for another, even if they work in the same industry sector" [29].

\subsection{Governance Capabilities}

IT governance capabilities have been defined as the "managerial ability to direct and coordinate the multifaceted activities associated with the planning, organisation and 
control of IT" [28]. According to the collective works of Peterson (2000, 2004), Weill and Woodham (2002), and Van Grembergen, De Haes and Guldentops (2005), three distinct governance capabilities include structures (connection), processes (coordination) and relational mechanisms (collaboration). Moreover, Grant et al. (2007) propose two further IT governance dimensions: temporal and external influences, which we believe are also important to consider in the context of a Living Lab.

\subsubsection{Structures}

The structures dimension represent formal and informal mechanisms that "encourage contacts and socialisation between stakeholder groups" [31]. Structures concern the existence of clearly defined roles and responsibilities and the establishment of steering committees and IT strategy committees [29]. Typically an "IT steering committee is situated at executive or management level and has the specific responsibility for overseeing major projects or managing IT priorities, IT costs, IT resource allocation, etc.”[29]. Grant, et al. [30] describes the structures dimension as constituting "tangible planning and organisational elements outlined by high-level governance strategy". These authors outline several forms of governance structures which are typically embodied within the structural capability: i) roles and responsibilities, ii) IT organisational archetypes and iii) management and steering committee structure. The establishment of competence and excellence centres, which enable the pooling of knowledge from different functional areas and enable an increased focus on developing valued business and IT skill sets, constitute a salient dimension of structural capability [28].

\subsubsection{Processes}

The processes dimension has been articulated as describing the "formal and informal activities that are planned and emerge during business IT initiatives e.g., organisation and evaluation of IT initiatives" and "the formalisation and institutionalisation of strategic IT decision making or IT monitoring procedures" [28]. The process dimension is primarily focused on the "integration of business and IT decisions, or the alignment of strategic IT investments with the strategic goals and objectives of the firm" [28]. The author outlines four levels of IT decision making process integration: administrative (budgets and schedules are amalgamated between business and IT), sequential (business decisions provide guidance for IT decision making), reciprocal (business and IT decisions carry collective credence) and full (concurrent operationalisation of IT and business decisions) integration. According to Grant et al., (2007) "the underlying principle of the process view is the recognition that IT governance is based on lateral decision making that extends beyond the walls of the traditional IT function into all parts of an organization...organisations must engage all levels of internal and external stakeholders in the establishment of an appropriate IT governance framework". These authors argue that the appropriate operationalisation of "ex post" monitoring mechanisms e.g., IT maturity alignment model, scorecards, cost benefit analysis, charge backs, service level agreements and so on, enables the ongoing control and evaluation of the IT governance structure. 


\subsubsection{Relational Mechanisms}

The structural and process IT governance capabilities working in tandem are not suited, given the mandatory tangible nature of both capabilities, for the design of effective IT governance architectures in dynamic and complex environments [31]. However, the operationalisation of the two aforementioned capabilities in conjunction with the intangible and tacit nature of relational capabilities can be quite cogent [28]. Relational mechanisms are "crucial in the IT governance framework and paramount for attaining and sustaining business-IT alignment, even when the appropriate structures and processes are in place" [29]. The relational capability dimension represents the requirement for the operationalisation of suitable mechanisms for ensuring effective relationship management amongst principal stakeholders. Relational mechanisms also incorporate unstructured strategic IT dialogues between principal stakeholders which can facilitate "rich conversation and communication to resolve diverging perspectives and stakeholder conflicts" [28]. Feurstein, et al. [17] posit that further research is warranted to determine how best to integrate society and citizens into Living Lab open innovation ecosystems. The authors argue that "as private persons become a source of ideas and innovations, an appropriate rewarding and incentive mechanism needs to be put in place which simultaneously secures pay-back to all the actors involved whilst adopting fair and suitable mechanisms for the handling of IPR (Intellectual Property Rights) and other ethical issues". In a distributed open innovation environment, it is important to create a 'cognitive minimum common denominator' amongst all the participant stakeholders in order to promote the development of shared values, shared trust and reciprocity [19]. Based on the analysis above the following propositions are delineated:

Proposition 1: Effective Living Laboratory IT governance is dependent on formalisation and institutionalisation of a high-level governance strategy, an appropriate IT organisational structure and the predefining of roles and responsibilities within the ecosystem.

Proposition 2: Effective Living Laboratory IT governance is dependent on the formalisation and institutionalisation of appropriate IT monitoring procedures/tools and also on the distribution of strategic IT decision making amongst internal and external stakeholders.

Proposition 3: Effective Living Laboratory IT governance is dependent on appropriate relational mechanisms which facilitate internal and external relationship management.

\subsubsection{Temporal}

The essence of the temporal dimension reflects that IT governance is a dynamic and continually evolving mechanism which must be continually monitored, controlled and evaluated to ensure that the IT governance remains aligned with the overall objective of the Living Lab initiative [30]. According to Grant et al., [30] the temporal dimension contains three separate elements: maturity (IT governance maturation model), life cycle (IT governance implementation will vary according to the stage in the life cycle of the governance process) and rate of change (IT governance approaches will 
differ depending on the stability or the agility of the Living Lab initiative). IT governance "develops over longer periods of time and credibility accumulation of experience and learning. Interpersonal relationships, coalitions through between stakeholders may take years to develop, to be able to effectively exploit information technology" [31]. For example, there is evidence to suggest that relational mechanisms are more influential at the initiating stages of IT governance [32], however no longitudinal research exists to confirm whether or not individual IT governance mechanisms have a more prominent role to play than others over time.

\subsubsection{External Influences}

It is generally accepted that the most cogent IT governance architecture for a given organisation is contingent on a variety of factors [33, 34]. Early research exploring how contingencies actively influenced IT governance arrangements identified factors such as corporate governance, economies of scope and absorptive capacity [35]. The IT governance institute identified a number of contingencies which consider size (computed by calculating turnover or staff numbers) industry type and geographical location [29]. More recently, the concept of an external influences dimension has been described as the manner in which the dynamics of environmental factors (e.g., socio-cultural, technological, legal/regulatory, political, economic, organisational and so on) mould IT governance arrangements and execution in real-world settings [30]. When designing a Living Laboratory IT governance architecture comprising structures, processes, temporal and relational mechanisms, it is important to note that these mix of mechanisms may be dependent on a multitude of externally influenced contingency factors which can influence the shaping of these mechanisms and subsequently impact on the IT governance outcome [29]. Given the absence of research in the area of Living Lab IT governance temporal mechanisms and external influencers, the following research can provide salient insight into not only the manner in which governance mechanisms have been moulded by contingency factors and the subsequent impact on the governance outcome, but also elucidate how IT governance has evolved over a period of time. Thus, two more propositions are presented.

Proposition 4: Effective Living Laboratory IT governance is time and context dependent as stakeholder experience, perceptions and expectations can lead to a realignment of IT governance.

Proposition 5: The chosen mix of structures, processes, temporal and relational mechanisms is dependent on multiple external influencers.

\subsection{Open Innovation Effectiveness}

Recent research into open innovation has focused on identifying select aspects of open innovation activities which make them effective e.g. vertical cooperation [36], costs of openness [37] and so on. There are differing opinions pertaining to what constitutes open innovation effectiveness. Cheng and Huizingh [38] explored whether the implementation of various open innovation activities resulted in greater innovation performance and concluded that effectiveness may be a multi-dimensional construct comprising multiple factors. Effectiveness may also include benefits such as offering 
an organisation a platform with which to measure an innovation's real value or to identify their core competencies [39]. The effectiveness of open innovation may also be determined by the resource endowments of the partnering organisation [40]. More importantly, Huizingh [41] argues that future research into open innovation effectiveness must venture beyond the "obvious consequences of lower costs, shorter time to market and more sales". This author also calls for research into case organisations where the open innovation process was ineffective. Despite the competitive advantage opportunities afforded by open innovation $[18,42]$, there are a number of risks which are inherent in the management of open innovation processes, for example, Morgan et al., [43] surmise that "the level of commitment, volume of knowledge exchange and successful alignment of objectives depends on the effective governance of resources and capabilities of all participants in a [collaborative open innovation] network." Likewise, the concept of a Living Lab encompasses multiple stakeholders working in close partnership and thus, the management of these relationships, through robust governance mechanisms, constitutes an essential component in the successful implementation of open innovation processes [44]. Thus, we present our final proposition:

Proposition 6: Open innovation effectiveness in living labs is dependent on the implementation and subsequent institutionalisation of an effective IT governance architecture.

We conclude our process of building a preliminary research model from extant research by presenting the constructs and relationships between them in Figure 1.

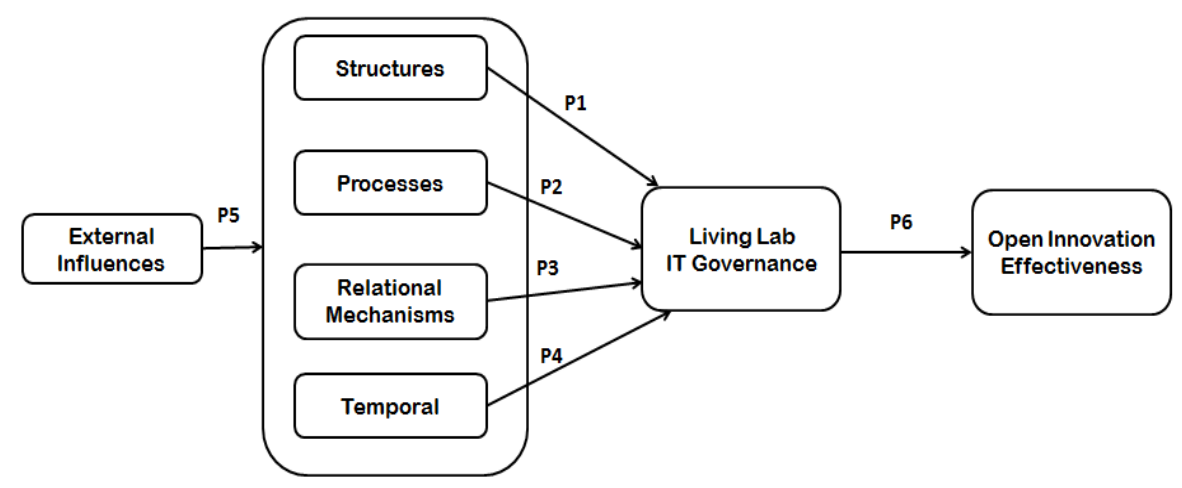

Fig. 1. Theoretical Model of Relationships and Constructs

\section{Conclusion}

Given the importance of IT governance in contemporary Living Lab initiatives, steering committees are faced with the challenge of how best to operationalize an IT governance mechanism that will facilitate effective open innovation processes. The theorising process employed in this study proved to be highly effective as the framework builds a basis for executing research on how Living Lab ecosystems are 
implementing IT governance and elucidate on the relationship between IT governance and open innovation effectiveness. Thus, in terms of future research we will concentrate on providing an empirically validated version of the research model proposed in this study, stipulating whether each dimension of the research model is applicable in the context of a Living Lab and if it can be substantiated. We believe an empirically validated research model will assist existing and new Living Lab initiatives reduce the risks encountered and support the management of emergent pathways that result as a consequence of operationalizing a particular IT governance mechanism.

Future research could also build on the findings to i) verify how IT governance implementations evolve over time ii) identify the core individual elements of effective IT governance mechanisms and iii) determine whether current Living Lab IT governance mechanisms are conducive for the future deployment of technologies in a smart city IT governance scenario.

Acknowledgment. This work was supported, in part, by Science Foundation Ireland grant 10/CE/I1855 to Lero - The Irish Software Engineering Research Centre (www. lero.ie).

\section{References}

1. Schaffers, H., Komninos, N., Pallot, M., Trousse, B., Nilsson, M., Oliveira, A.: Smart cities and the future internet: Towards cooperation frameworks for open innovation. In: Domingue, J., et al. (eds.) Future Internet Assembly. LNCS, vol. 6656, pp. 431-446. Springer, Heidelberg (2011)

2. Kroes, N.: The critical role of cities in making the digital agenda a reality. European Commission. Press Release (2010), http: / / europa . eu/rapid/ press-release_SPEECH-10-272_en.htm

3. Kanter, R., Litow, S.: Informed and interconnected: A manifesto for smarter cities. Harvard Business School General Management Unit Working Paper, pp. 09-141 (2009)

4. Batty, M., Axhausen, K., Giannotti, F., Pozdnoukhov, A., Bazzani, A., Wachowicz, M., Ouzounis, G., Portugali, Y.: Smart cities of the future. The European Physical Journal Special Topics 214(1), 481-518 (2012)

5. Von Hippel, E.: Democratizing innovation: The evolving phenomenon of user innovation. Journal für Betriebswirtschaft 55(1), 63-78 (2005)

6. Nam, T., Pardo, T.A.: Conceptualizing smart city with dimensions of technology, people, and institutions. In: Proceedings of the 12th Annual International Digital Government Research Conference, Digital Government Innovation in Challenging Times. ACM (2011)

7. Johnston, E.W., Hansen, D.L.: Design lessons for smart governance infrastructures. American Governance 3 (2011)

8. Hernández-Muñoz, J.M., Vercher, J.B., Muñoz, L., Galache, J.A., Presser, M., Gómez, L.A.H., Pettersson, J.: Smart cities at the forefront of the future internet. In: Domingue, J., et al. (eds.) Future Internet Assembly. LNCS, vol. 6656, pp. 447-462. Springer, Heidelberg (2011)

9. Ballon, P., Glidden, J., Kranas, P., Menychtas, A., Ruston, S., Van der Graaf, S.: Is There a Need for a Cloud Platform for European Smart Cities? In: eChallenges e-2011 Conference Proceedings, pp. 1-7 (2011) 
10. Eriksson, M., Niitamo, V.-P., Kulkki, S.: State-of-the-art in utilizing Living Labs approach to user-centric ICT innovation-a European approach. Center for Distance-spanning Technology. Lulea University of Technology Sweden, Lulea (2005),

http://www.vinnova.se/upload/dokument/verksamhet/tita/ stateoftheart_livinglabs_eriksson2005.paf

11. Lichtenthaler, U., Ernst, H.: Attitudes to externally organising knowledge management tasks: A review, reconsideration and extension of the NIH syndrome. R\&D Management 36(4), 367-386 (2006)

12. Chesbrough, H.: Open Innovation: Where We've Been and Where We're Going. Research Technology Management 55(4), 20-27 (2012)

13. Chesbrough, H., Vanhaverbeke, W., West, J.: Open Innovation: Researching a New Paradigm. Oxford University Press, Oxford (2006)

14. Lichtenthaler, U.: Open innovation in practice: An analysis of strategic approaches to technology transactions. IEEE Trans. Eng. Manage. 55(1), 148-157 (2008)

15. van de Vrande, V., Vanhaverbeke, W., Gassmann, O.: Broadening the scope of open innovation: past research, current state and future directions. Int. J. Technol. Manage. 2(3-4), 221-235 (2010)

16. Pallot, M.: The Living Lab Approach: A User Centred Open Innovation Ecosystem. Webergence Blog 2010 (2009)

17. Feurstein, K., Hesmer, A., Hribernik, K., Thoben, K., Schumacher, J.: Living Labs: A new development strategy. In: Schumacher, J., Niitamo, V.-P. (eds.) European Living Labs: A New Approach for Human Centric Regional Innovation, Wissenschaftlicher Verlag (2008)

18. Chesbrough, H.: Open Innovation: The New Imperative for Creating and Profiting from Technology. Harvard Business School Press, Boston (2003)

19. Sawhney, M., Prandelli, E. (eds.): How organizations learn: Managing the search for knowledge, p. 271. Cengage Learning EMEA (2004)

20. Howe, J.: The rise of crowdsourcing. Wired Magazine 14(6), 1-4 (2006)

21. Bergvall-Kareborn, B., Stahlbrost, A.: Living Lab: An open and citizen-centric approach for innovation. International Journal of Innovation and Regional Development 1(4), 356-370 (2009)

22. Dubin, R.: Theory building. Free Press (1978)

23. Whetten, D.A.: What constitutes a theoretical contribution? Academy of Management Review 14(4), 490-495 (1989)

24. Reynolds, P.: Primer in theory construction, An a\&b classics edition. Allyn \& Bacon, Needham Heights (2006)

25. Brown, A., Grant, G.: Framing the frameworks: A review of IT governance research. Communications of the Association for Information Systems 15 (2005)

26. Weill, P.: Don't just lead, govern: How top-performing firms govern IT. MIS Quarterly Executive 3(1), 1-17 (2004)

27. Singh, H.: A Practice Theory View of IS Governance. In: Proceedings of the JAIS Theory Development Workshop - SPROUTS: Working Papers on Information Systems, vol. 9(52) (2009)

28. Peterson, R.: Crafting information technology governance. Information Systems Management 21(4), 7-22 (2004)

29. De Haes, S., Van Grembergen, W.: IT governance structures, processes and relational mechanisms: Achieving IT/business alignment in a major Belgian financial group. In: Proceedings of the 38th Annual Hawaii International Conference. IEEE (2005)

30. Grant, G., Brown, A., Uruthirapathy, A., McKnight, S.: An Extended Model of IT Governance: A Conceptual Proposal. In: AMCIS Proceedings (2007) 
31. Peterson, R.: Emerging Capabilities of Information Technology Governance: Exploring Stakeholder Perspectives in Financial Services. In: Proceedings of the 8th ECIS, pp. 667-675 (2000)

32. De Haes, S., Van Grembergen, W.: An exploratory study into IT governance implementations and its impact on business/IT alignment. Information Systems Management 26(2), 123-137 (2009)

33. Brown, C.V., Magill, S.L.: Alignment of the IS Functions with the Enterprise: Toward a Model of Antecedents. MIS Quarterly 18(4), 371-404 (1994)

34. Brown, C.V.: Examining the emergence of hybrid IS governance solutions: Evidence from a single case site. Information Systems Research 8(1), 69-94 (1997)

35. Sambamurthy, V., Zmud, R.W.: Arrangements for information technology governance: A theory of multiple contingencies. MIS Quarterly, 261-290 (1999)

36. Tomlinson, P.R.: Co-operative ties and innovation: Some new evidence for UK manufacturing. Research Policy 39(6), 762-775 (2010)

37. Laursen, K., Salter, A.: Open for innovation: The role of openness in explaining innovation performance among U.K. manufacturing firms. Strategic Management Journal 27(2), $131-150$ (2006)

38. Cheng, C., Huizingh, K.: Open innovation to increase innovation performance: Evidence from a large survey. In: Proceedings of the XXI ISPIM International Conference, vol. 6(9) (2010)

39. Rigby, D., Zook, C.: Open-market innovation. Harvard Business Review 80(10), 80-93 (2002)

40. Dahlander, L., Gann, D.M.: How open is innovation? Research Policy 39(6), 699-709 (2010)

41. Huizingh, E.K.: Open innovation: State of the art and future perspectives. Technovation 31(1), 2-9 (2011)

42. Enkel, E., Gassmann, O., Chesbrough, H.: Open R\&D and open innovation: Exploring the phenomenon. R\&D Management 39(4), 311-316 (2009)

43. Morgan, L., Feller, J., Finnegan, P.: Open source innovation networks: Exploring high and low-density models. In: Proceedings of PACIS (2012)

44. Feller, J., Finnegan, P., Hayes, J., O’Reilly, P.: Institutionalising information asymmetry: Governance structures for open innovation. Information Technology \& People 2(4), 297-316 (2009) 